\title{
Planning of the territory of large cities of Russia in the interests of their sustainable development
}

\author{
Olga Popova ${ }^{1}$, Marina Perekopskaya ${ }^{1 *}$ and Galina Godunova ${ }^{2}$ \\ ${ }^{1}$ Northern Arctic Federal University named after M. V. Lomonosov, Department of roads and \\ construction industry, Arkhangelsk, Russia \\ ${ }^{2}$ Moscow State University of Civil Engineering, 26 Yaroslavskoye Shosse, 26, Moscow, 129337, \\ Russia
}

\begin{abstract}
The paper reported here analyzes the practice of preparing documentation on territory planning in large cities of the North-West Federal district of Russia. Particular attention is paid to the development of projects on the basis of proposals of individuals or legal entities, as well as the search for effective tools for the development of cities of the North-West Federal district of Russia. The authors propose an alternative version of the interaction of local governments with potential investors on urban planning documentation. The mechanism of formation and updating of design solutions is based on a comprehensive assessment of incoming urban planning proposals of stakeholders.
\end{abstract}

\section{Introduction}

Investment activities remain one of the major tools of Russian cities' development. Being a multi-faceted and extremely complex process, investment activities in different cities of the country are usually designed taking into account the specifics of their development. There are a number of objective restrictions of large investments inflow and utilization in the cities of Russia imposed both by the external processes, and the investment climate in every municipality. Competition for attracting investments is escalating in the external environment. The investment climate inside is also to be improved by the authorities. In large cities, there are many problems that constrain the inflow of investment: legal, administrative, infrastructure, personnel, methodological and a number of others.

The determining factor of economic development of cities is land relations [1]. "Land" is considered as a set of land plots of publicly-organized system that provides effective development of the territory in accordance with the established objectives. Land management, provision of land plots for facilities construction, development of initial permits necessary for this purpose is very specific and difficult in Russia at present moment. Preparation of initial permits is included in the list of main tasks, the solution of which is necessary for the provision of land for construction, as well as for land use regulation. A significant role in the structure of the initial permitting documentation is assigned to strategic and urban planning.

\footnotetext{
*Corresponding author: mappi25@yandex.ru
} 
The economic situation in large Russian cities, the gradual transformation of demand in the real estate market, the introduction of public-private partnership mechanisms into various fields of public life, require rapid adaptation of urban planning documentation. Changes in strategic directions and spheres of investment activity in cities should ensure accelerated development of a municipality, its peculiarities being taken into consideration [10].

The traditional object of planning in urban design is urban space, its qualitative and quantitative characteristics are: the architectural and planning organization, the spatial characteristics of industrial areas, housing sector, the public services sector, engineering infrastructure, transport infrastructure, environmental conditions [2].

The processes of strategic and urban planning are closely related [9]. The main purpose of the strategic planning for the area socio-economic development can not be achieved without adequate spatial development framework.

At the same time, management of urban development of the territory, focused on the increase of investment attractiveness, is impossible without timely strategic planning. It is the strategy that determines the conditions for the development of the territory, the needs for labor and financial resources corresponding to the type and volume.

Increasingly intensifying processes of asymmetric social and economic development of separate territories require a reliable mechanism to identify investment potential of municipality put in place, its emergence and development being the primary task [11]. At the local level, this task is carried out through the development of documentation on the planning of the territory to ensure its sustainable development.

In many respects, the solutions for the documentation on the territory planning stem from the existing initiatives of citizens and business entities. They also result from the need to observe the balance of interests and the need to comply with urban planning, sanitary, epidemiologic and other standards.

Changes in the structure of the territory planning documentation and the procedure for the preparation and content of the urban plan made by the legislator in 2017 , require a corresponding transformation of the scientific approach to creating a favorable investment climate in large cities. Guidelines or model clauses that would provide a mechanism of interaction between the municipality and stakeholders while making and updating planning decisions aimed at enhancing investment activity must be produced.

\section{Materials and Methods}

The objects of the research are the projects of the territory planning in large cities of the northwestern Federal district of Russia [8], which were developed and approved in the period from 2006 to 2017. Such cities of the North-West Federal district as Arkhangelsk, Vologda, Kaliningrad, Murmansk, Petrozavodsk meet these selection criteria [3-7].

The study summarizes the practice of development and approval of documentation on the planning of the territory.

All approved by above mentioned municipalities territory planning projects are assessed for compliance with requirements of the Urban Planning Code of the Russian Federation which were in force at the moment of their approval (the first group of criteria) as well as the requirements for territory planning projects imposed by the current version of the Code (the second group of criteria).

The weighting parameters are determined by the expert method of preference, based on the practical experience of implementing the approved documentation on the territory layout.

The shortcomings of the approved territory planning projects having been identified in the process of evaluation allow determining their causes and proposing appropriate preventive measures. 
Table. Evaluation criteria for planning projects

\begin{tabular}{|c|l|c|c|}
\hline № & \multicolumn{1}{|c|}{ The name of the criterion } & Score & Weight \\
\hline \multicolumn{1}{|c|}{ The first group of criteria } \\
\hline 1 & Availability of required structural elements & 1 & 0.1 \\
\hline 2 & $\begin{array}{l}\text { Availability of design solutions to provide the territory with } \\
\text { social infrastructure }\end{array}$ & 1 & 0.2 \\
\hline 3 & $\begin{array}{l}\text { Availability of design solutions to provide the territory with } \\
\text { engineering infrastructure }\end{array}$ & 1 & 0.2 \\
\hline 4 & $\begin{array}{l}\text { Availability of design solutions to provide the territory with } \\
\text { transport infrastructure }\end{array}$ & 1 & 0.25 \\
\hline 5 & Zones with specific terms of use are established and reflected & 1 & 0.25 \\
\hline Total & \multicolumn{1}{|c|}{ The second group of criteria } & 1 \\
\hline & \multicolumn{2}{|c|}{} \\
\hline 1 & Plans for development of the territory have been prioritized & 1 & 0.1 \\
\hline 2 & $\begin{array}{l}\text { Variants of planning and (or) spatial solutions for buildings are } \\
\text { presented }\end{array}$ & 1 & 0.2 \\
\hline 3 & The red lines meet the requirements of the established rules & 1 & 0.25 \\
\hline 4 & The results of engineering surveys are of the prescribed amount & 1 & 0.25 \\
\hline 5 & $\begin{array}{l}\text { The boundaries of zones planned for capital construction } \\
\text { projects are determined }\end{array}$ & 1 & 0.2 \\
\hline Total & & 1 \\
\hline
\end{tabular}

\section{Results and Discussion}

The study revealed that Kaliningrad and Vologda were the first to introduce preparation and approval of documentation on the planning of the territory. At the same time, in Kaliningrad all the interested parties were actively involved in the preparation of documentation on the planning of the territory from the very beginning.

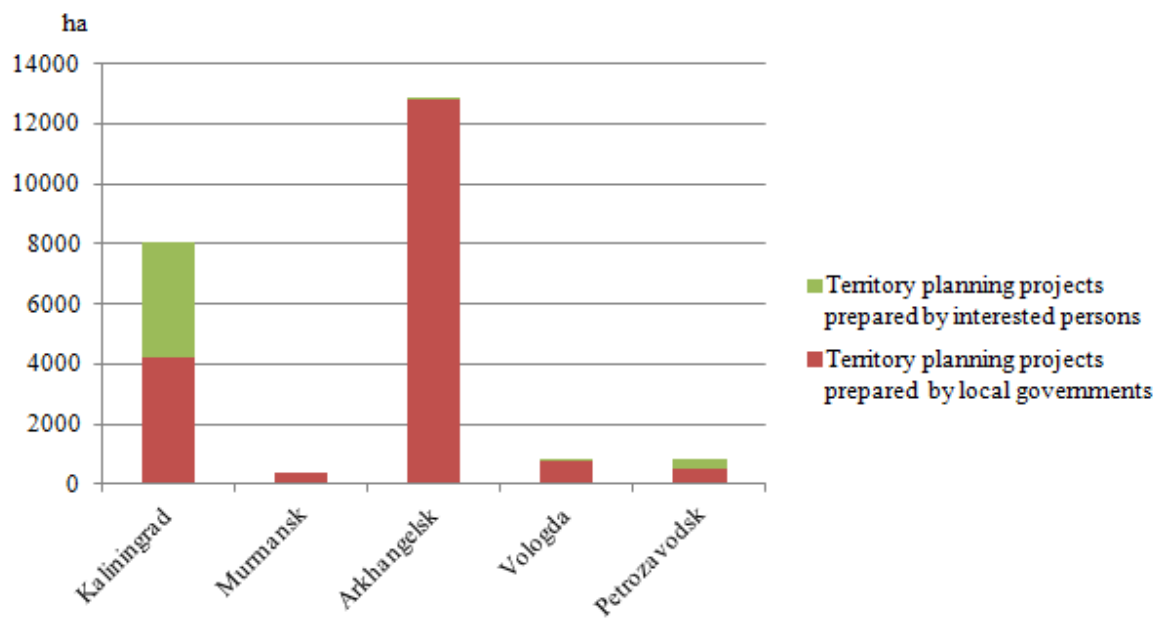

Fig. 1. Indicators of participation of subjects of urban planning activity in preparation of territory planning projects

In general, investors prepared 47.5 percent of the territory planning projects during the period under consideration [5]. The active participation of interested persons in providing 
Kaliningrad with documentation on the planning of the territory is largely due to its high investment attractiveness among the major cities of the North-West Federal district, especially in the field of housing construction. In Petrozavodsk stakeholders prepared 34.4 percent of the planning projects [7], and in Vologda only 12 percent [4]. At the same time, the area of the territory provided with planning documentation is very small. In Arkhangelsk and Murmansk the practice of preparation of documentation on the territory planning by interested persons is practically not applied $[3,6]$ which is confirmed by the data presented in figure 1. This is due to the strategic goals of these municipalities, physical or geological processes occurring in the vacant territories, low level of engineering and transport infrastructure already existing there.

In characterizing dynamics of preparation of documentation on the planning of territories in the large cities of the Northwest Federal district during the period under consideration, note should be taken that peak period of activity is 2014-2015 (figure 2). At the same time, most of the projects of this period were prepared and approved in Arkhangelsk and Kaliningrad [3,5].

Territory planning projects in the cities under review are focused mainly on the reconstruction, urban densification and establishing order among existing elements of the urban development pattern

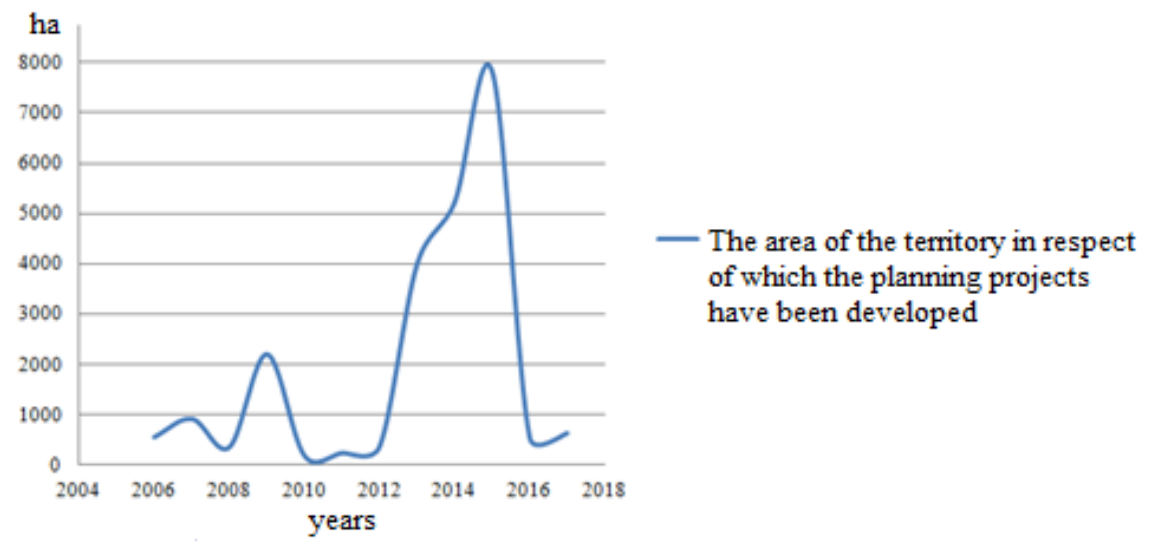

Fig. 2. The preparation of territory planning projects in the major cities of NWFD dynamics.

The territory planning projects developed and approved in the period from 2006 to 2017 having been assessed, the following was established for the first and second group of criteria.

All the territory planning projects prepared due to initiative of local governments fully meet the requirements for planning documentation imposed by the Urban Planning Code of the Russian Federation and which were in force at the moment of their approval.

As for territory planning projects prepared by the persons concerned, those adopted in 2006 fully comply with the requirements in force at the time of their approval. The lowest scores (ranging from 0.7 to 0.8 points) were obtained by one residential project in 2007 (design area of 158.3 hectares), one residential project in 2008 (design area of 50.2 hectares) and two residential projects in 2009 (design area of 314.8 hectares) (figure 3). 


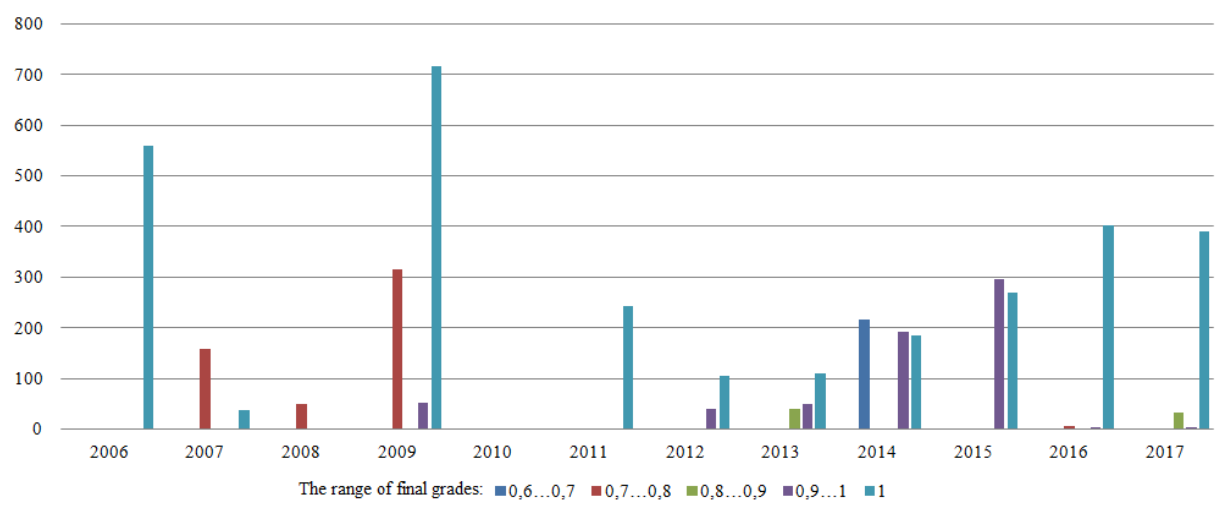

Fig. 3. The results of the evaluation of projects in the cities of NWFD against the first group of criteria

The low rating is due to the fact that there are no design solutions to provide the territory with social and engineering infrastructure or they are not fully presented (in one case), existing zones with specific terms of use of the territory are not established and not reflected (in three cases) and some mandatory structural elements are absent (in three cases).

Assessing the territory planning projects prepared due to the initiative of local governments in terms of the second group of criteria, it can be noted that $6 \%$ of the territory is provided with documentation that meets the requirements imposed by the current version of the Urban Planning Code of the Russian Federation, 20\% of the territory is provided with documentation that has received an assessment in the range from 0.9 to 1 point and $70 \%$ of the territory is provided with documentation that has received an assessment in the range from 0.8 to 0.9 points (figure 4 ).

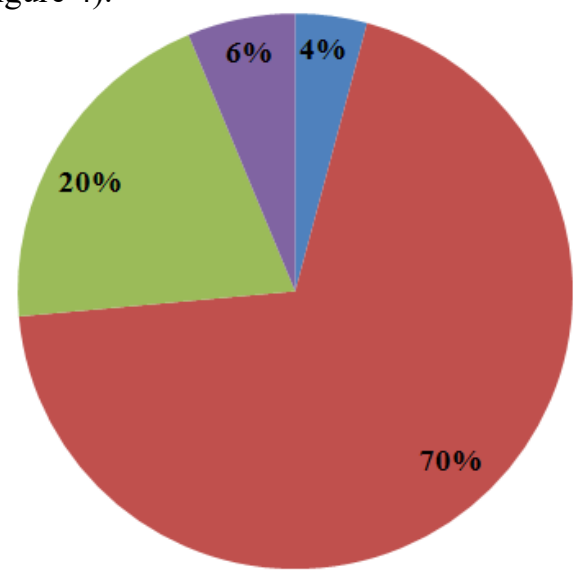

The range of final grades: $\square 0,7 \ldots 0,8 \quad \square 0,8 \ldots 0,9 \quad \square 0,9 \ldots 1 \quad \square 1$

Fig. 4. The results of the evaluation of projects in the cities of NWFD, prepared due to initiative of local governments, against the second group of criteria

The results of the evaluation of territory planning projects prepared by the stakeholders, according to the second group of criteria, demonstrate even lower final scores (figure 5). 


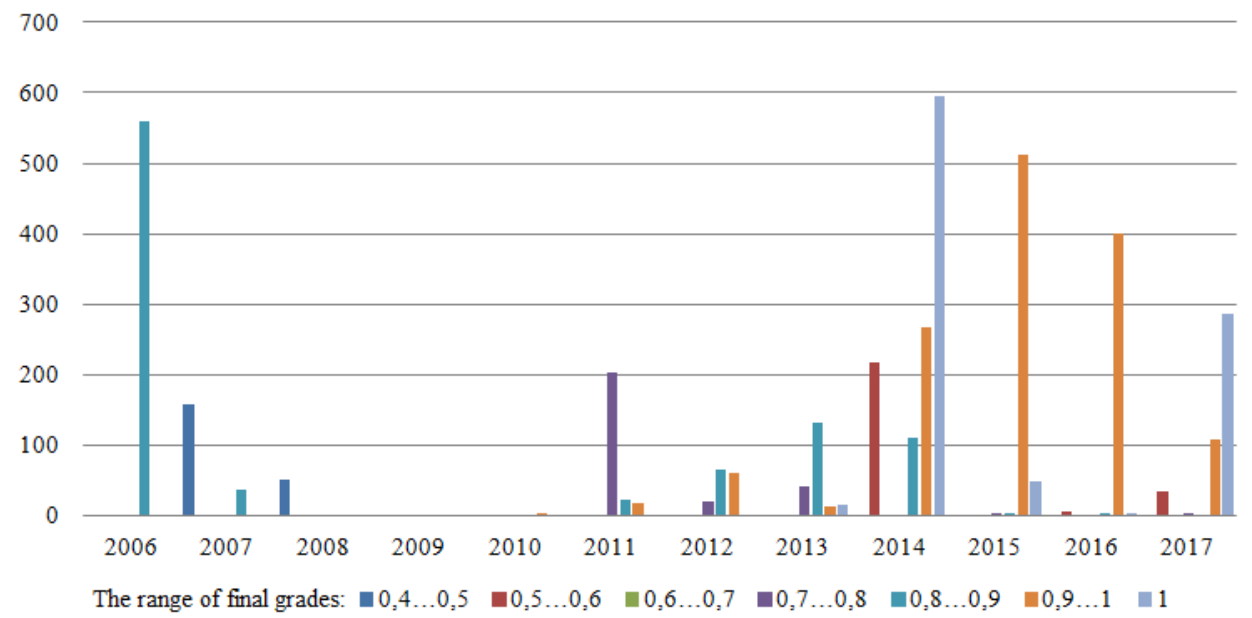

Fig. 5. Results of the evaluation of the projects prepared by the interested parties according to the second group of criteria

The most common drawbacks of both categories of projects were:

1. Absence of boundaries of zones planned for several projects of capital construction;

2. Lack of information on how plans for development of the territory have been prioritized;

3. Nonconformity of the red lines marked in the graphic part of the project with the requirements of the established rules.

It is possible to specify the following causes of the revealed shortcomings of territory planning projects according to the first group of criteria:

1 . Boundaries of territory to be planned.

The cost of design work is in direct proportion to the area of the design. In order to reduce costs, interested persons are willing to develop urban planning documentation only within the boundaries of their land. At the same time, attention paid to the analysis of transport links, to the location of the territory being planned in the urban structural pattern and its functional purpose is not enough. The intensity of use of functional zones by residents, the access to them and possible changes in the density of objects located in the territory being planned are not taken into consideration.

2. Human resources of the organizations-developers.

In order to prepare projects interested persons often apply to land-surveying or project companies. The staff of these organizations does not possess the necessary knowledge in the field of urban planning.

The main reason for the identified shortcomings of the territory planning projects according to the second group of criteria is the continuing reformation of the urban development sector, adoption of new and changing the current requirements.

Given that the deadline for all the projects has not passed yet, their further implementation require changes in terms of bringing documentation into compliance with the requirements of the Urban Planning Code of the Russian Federation. Particular attention should be paid to projects prepared by stakeholders that received low ratings according to the first and second groups of criteria.

Despite the possibility of preparing documentation on the planning of the territory by interested persons, the local authorities should retain this function and involve urban planning institutes. This is due to the need for a comprehensive urban development analysis of the territory in terms of:

- location of the territory being planned in the urban structural pattern 
- possible functional purpose;

- intensity of use of functional zones, the access to them being taken into consideration;

- possible changes in the density of objects located in the territory being planned .

Involvement of citizens and subjects of economic activity in the development of urban planning solutions is possible, their suggestions on urban planning and erecting facilities should be taken into account. The mechanism of interaction of local governments with interested parties can be developed according to the scheme provided in figure 6 .

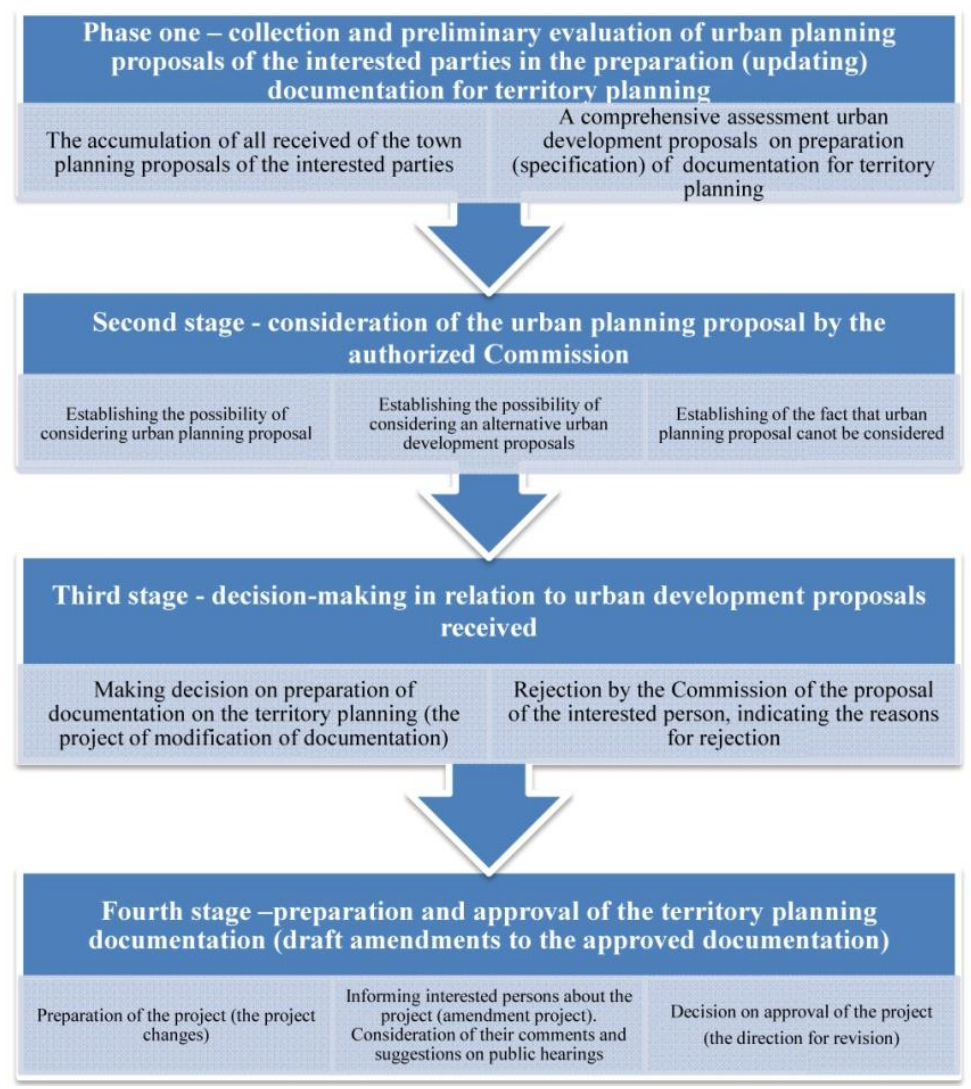

Fig. 6. The mechanism of interaction of local authorities with the interested parties in support of urban planning proposals consideration

\section{Conclusions}

High-quality architecture and comfortable living environment are central to the preparation of the territory planning projects. Development of the territory in terms urban planning assumes the account of both initiatives of citizens and subjects of economic activity, and observance of urban planning, sanitary and epidemiologic and other norms. In general, urban planning solutions should meet the needs of present generations without compromising the ability of future generations to meet their own needs.

Proceeding from it, participation of citizens and subjects of economic activity in the development of urban planning solutions is possible only in the form of making proposals on urban planning and erecting facilities. On the other hand, local authorities should take their suggestions into consideration and implement a comprehensive urban planning analysis of these proposals. 
The mechanism of interaction of local governments with interested persons presented in this article allows to make this interaction more open and to reduce administrative barriers by means of suggesting alternative territory planning solutions.

\section{References}

1. T. Kramkova, Property relations in the RF. J. 4, 41 (2013)

2. V. Masch, Journal of Urban Management, J. 1 (2), 6 (2012)

3. Materials of the official website of Arkhangelsk. - URL: http://www.arhcity.ru

4. Materials of the official website of Vologda. - URL: http://vologda-portal.ru

5. Materials of the official website of Kaliningrad. - URL: http://www.klgd.ru

6. Materials of the official website of Murmansk. - URL: http://www. citymurmansk.ru

7. Materials of the official website of Petrozavodsk. - URL: http://www.petrozavodskmo.ru

8. Federal state statistics service - URL:http://www.gks.ru;

9. European Charter for Regional / Spatial Planning (Torremolinos Charter) - URL: http://docs.cntd.ru

10. J. Poot, S. Pawar, Journal of Urban Management, J. 2 (1), 5 (2013)

11. P.Janež, M.Bogataj, S. Drobne, GV. J. 60, 646 (2016) 